\title{
Mutual Open-mindedness set in Motion in Afghanistan
}

\section{GES AND ASCHIANA \\ - A PARTNERSHIP IN ENABLEMENT}

GES (Global Education through Sport), founded in 2004, is a Danish Sports Non-Governmental Organization (NGO). Aschiana (Afghan Street Working Children and New Approach) and GES continue to partner a sports project in Kabul, Afghanistan, that was initiated in 2004. This partnership resulted from a request by Aschiana for assistance to launch sports activities at its centers. Aschiana is an Afghan NGO founded in March, 1995, in Kabul. In the Persian language, 'aschiana' means "the nest", and symbolizes the function of the Aschiana centers as safe havens for street-working children and youth. Aschiana offers free education and one meal a day as well as other supplies to the children and youth. The organization teaches them to cope with their problems, gain self-confidence and develop the competences needed for this marginalized group to become stronger individuals.

GES and Aschiana aim to give the street-working children and youth the opportunity to do sports and through these activities, to learn different social skills as well as to develop both mentally and physically. To sustain its aim, GES

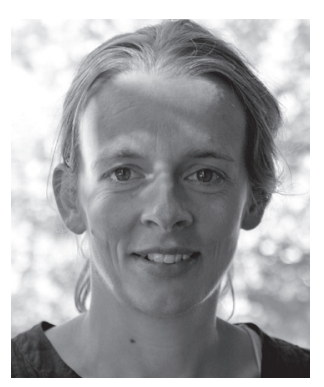

BY

MAJBRIT

KRONBORG

MOURIDSEN

developed capacity building programs for Afghan Physical Education (PE) teachers working at the Aschiana centers, enabling them to run regular sports education training for the boys and girls. This article describes the methods that characterize the sports development collaborative project between GES and Aschiana.

\section{EDUCATING AFGHAN PE TEACHERS}

The aim with the project was to prepare the Aschiana PE teachers to educate children and youth through sports, thus promoting social capital and contributing more generally to strength- 


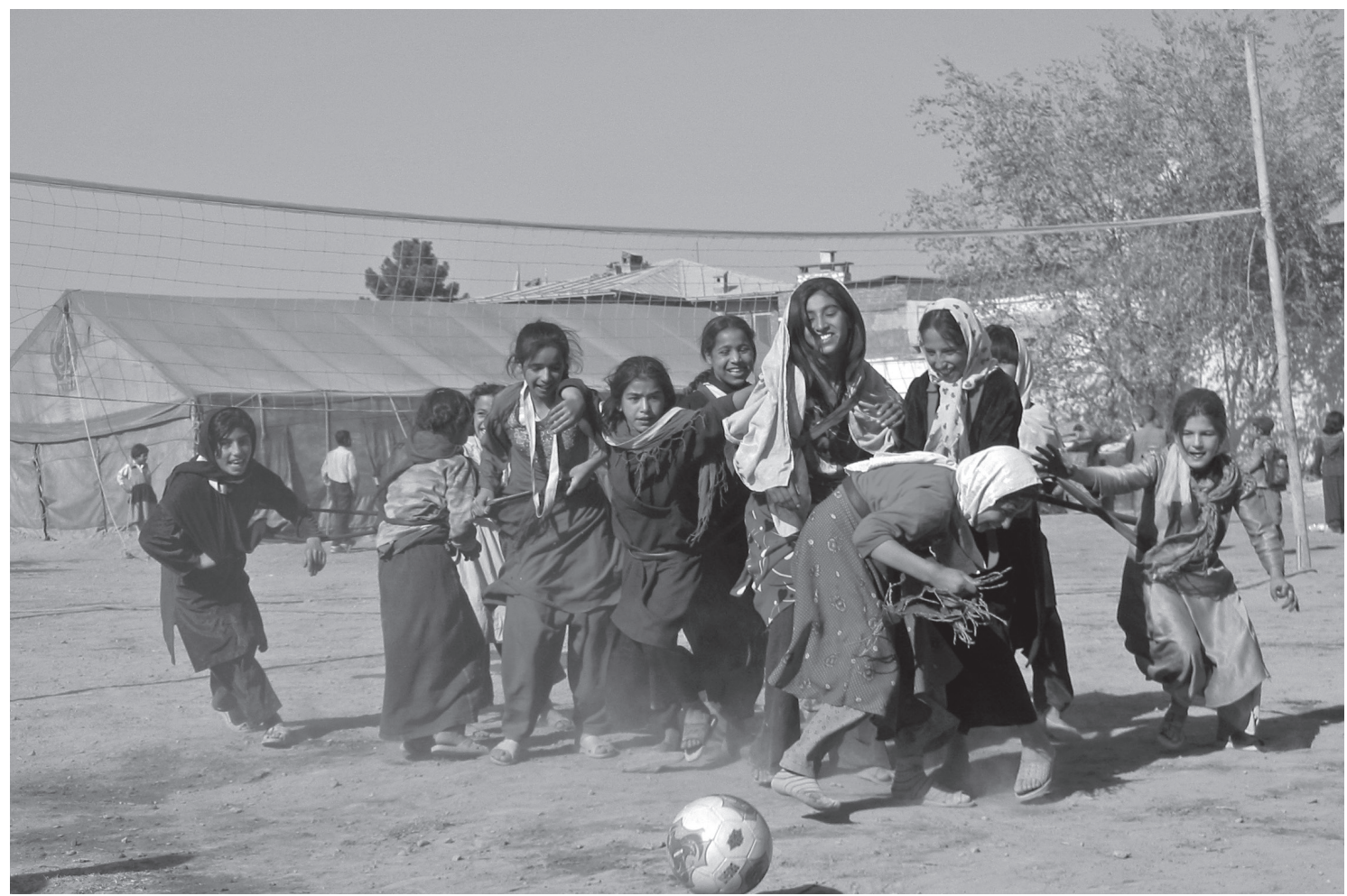

Collaborative soccer at Aschiana - Girls in fight for the ball (Photo: Majbrit Mouridsen).

ening the local civil society. GES wanted to detail the project's content and methods in collaboration with the Aschiana staff. It proved to be important for the Aschiana PE teachers to start with something concrete and practical training through sports activities was determined to be the most suitable entry point for the project. After assessing the needs and abilities of Aschiana, four main sports disciplines were identified as the foundation for the project. These included judo, basketball, football and volleyball and lessons on safety, game rules and $\mathrm{PE}$ planning were then integrated in the train- ing. Each local PE teacher focused on one or two disciplines in order to gain expertise in the specific disciplines. The main objectives of this practical part of the training program were: to enable the Afghan PE teachers to practise different basic technical skills; gain motivation; and obtain an understanding of how to develop a progressive lesson where the children could have fun while learning new skills. Parallel workshops on different subjects were organized, including: the value in sports; communication; responsibility; motivating children; using fun games; fair play; and social behaviour. 
In parallel with the training, the Afghan PE teachers applied the new knowledge in their lessons with the children. At first, the Danish GES staff supervised and evaluated training sessions together with the Afghan PE teachers in order to learn from each other's successes and failures. This was the start of the project's content development. Later, more specific training was provided in physiology, anatomy, psychology, health and tournament organization.

The Afghan PE teachers were excited to gain new knowledge and expressed pleasure in teamwork, the teaching methods and the use of fun games. The knowledge communicated during the process was recorded in the local language and collected in compendiums for better accessibility by the local PE teachers. The teachers were tested on their knowledge in some segments of the training program to confirm their understanding of the content. This seemed to motivate them, as did receiving diplomas on the successful completion of their training.

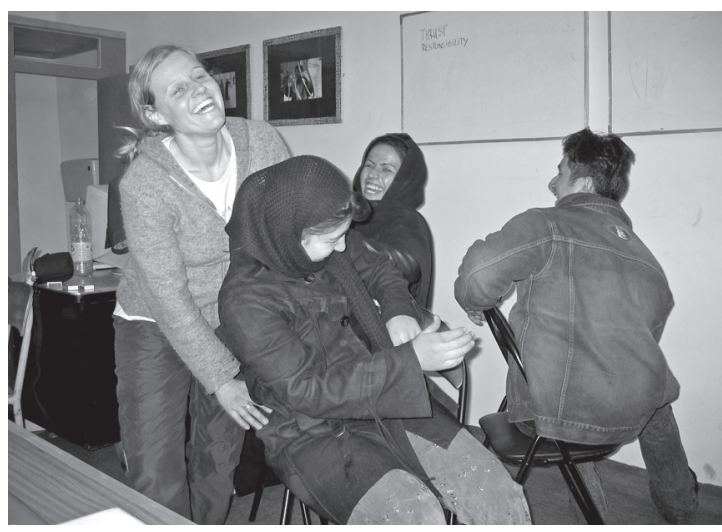

Afghan and Danish PE teachers learn to know each other through icebreaker exercise (Photo: Majbrit Mouridsen).

\section{SOCIAL RELATIONS AND TEAM SPIRIT AS KEY MOTIVATORS}

The overall approach to capacity building was to use facilitative methods and hereby reach common aims. This primarily required instilling a sense of open-mindedness within the group towards each other as well as towards the project objectives and the methods. The Danish facilitators started by expressing their understanding of the relationships within the group through visualization. Using a soccer field, each Afghan and Danish staff member was a player with different roles and competences yet part of the same team. This approach framed the fundamental values of cooperation, equality, respect, and acceptance. Playing fun games, doing sports together and discussions built up relationships within the team of Danish and Afghan staff. It was crucial for future cooperation within the team to prioritize building good relationships that could lead to taking an interest in and understanding each other as well as promoting openness where honesty and cooperation could flourish. The open-minded environment also made it possible for everybody to influence and learn from each other across gender, nationality, education, age, status, and experience. The Danish and the Afghan staff members felt that they were one team implementing the project, which was especially important considering that often many developmental projects create a gap between facilitators from abroad and local development workers. The success was based on the fact that everybody took the time to get to know each other and took responsibility for participating in the process and remaining open to each other's opinions and ideas. The team members got to know each other as individuals and not as stereotypes. 


\section{CREATING THE WORK TOOL}

Openness to learning new sports skills and organizing activities was easy at first, but the objectives that GES believed to be central to the sport development project were more complex. The GES staff considered that the approach the Afghan PE teachers should take was to use sports as a tool to educate, socialize and empower the children and youth and guide them to becoming better citizens. This approach had little meaning for the Afghan staff who, instead, were motivated by and busied themselves with learning how to organize and run physical activities. They focused on mastering basic skills and ensuring that participants excelled in sport disciplines for the purpose of competition. This approach in itself did exhibit the values of team bonding and achieving good results. When the two different approaches were brought to the table, both the Danish and the Afghan staff had already achieved a sense of openness towards each other and a resolution was found. In retrospect, however, it would not have been possible to start using sports as a work tool before the tool was actually created and refined. However, the overall project plan did not consider the complexity of organizing and running basic sports activities. One major oversight in the plan was the need for deeper analysis of the capacity of the Afghan PE teachers and the institutional and organizational sports structures. This flaw prevented the intended use of sports as an initial work tool. Instead, the process began by teaching the Afghan PE teachers the basic technical skills involved in the different sports activities, including organizational and pedagogical aspects. These activities simultaneously produced social benefits that were initial objectives of the project. One example of this was the benefit of inclusiveness, expressed in the project by making the sports available and fun for all of the children and youth at the Aschiana centers. By realizing the capacities and motivation of the Afghan PE teachers, the project came closer to meeting the local contextual needs.

\section{COMMUNICATION AND FEEDBACK}

Linguistic and cultural differences between the Danish and the Afghan staff did slow the educational process and misunderstandings resulted in long sessions to clarify each other's understanding. One example of a misunderstanding is the fact that learning in the Afghan schools is characterized by doing what the teacher says

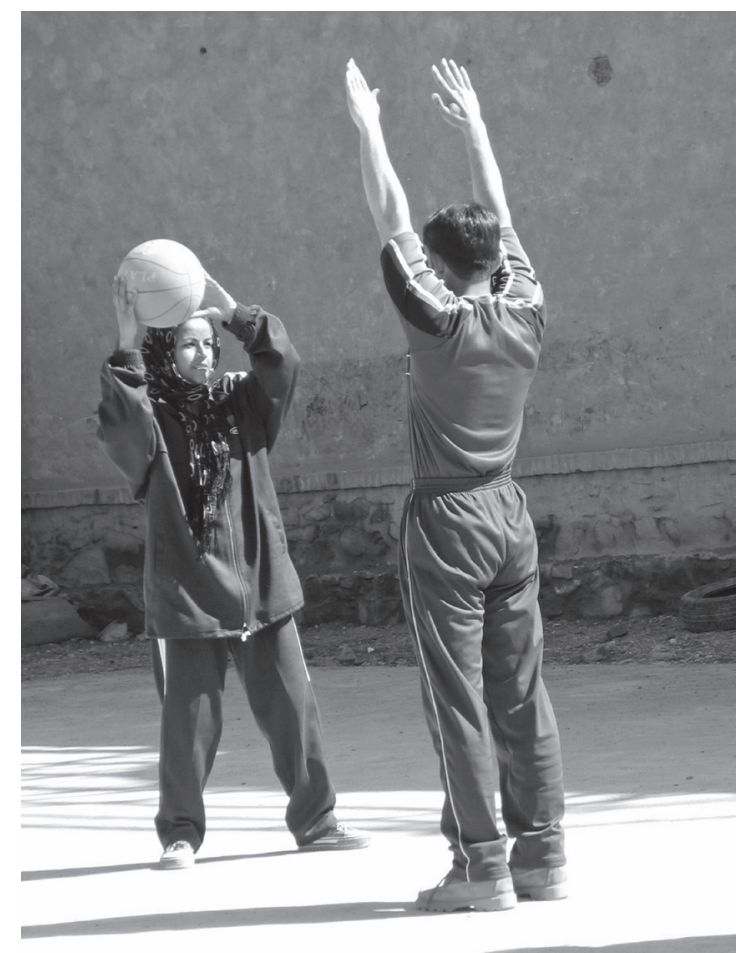

The Afghan PE teachers train their basketball skills (Photo: Majbrit Mouridsen). 


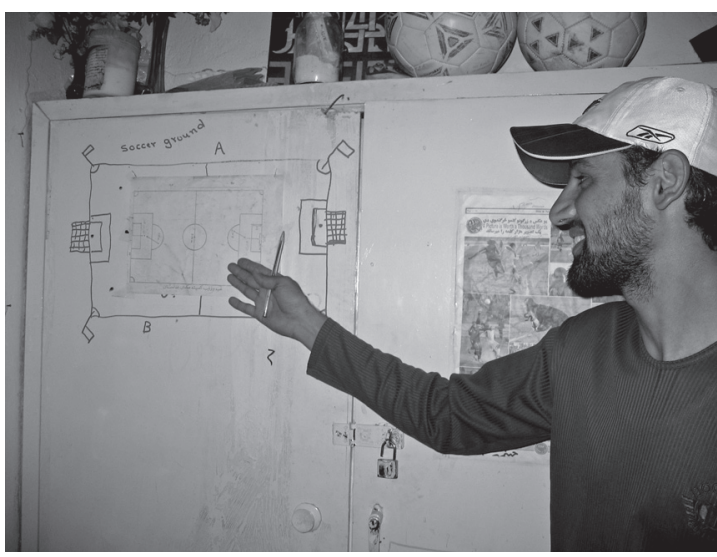

PE teachers from Aschiana explain soccer rules to the children before training (Photo: Majbrit Mouridsen).

while the approach of the project and the Danish staff called for self-directed learning. The positive effect of the differences in understanding and language was that it created room for dialogue. Methods like visualization, exemplification, role-play, etc. were helpful in avoiding misunderstandings and in facilitating an exciting and participatory learning environment. Training in sports skills appealed to the Afghan $\mathrm{PE}$ teachers as they were interested in physical activities and they always had interesting reflections to share with the others during workshops.

Feedback was used throughout the learning process, with the intention of creating a deeper conceptual understanding among the participants. Compendiums were written during the training program and included the contextual reality. It was much easier to promote conceptual thinking by referencing experiences and examples that the participants had tried themselves. The opportunity to personally practise new skills and to become involved in trying things was especially useful to the Afghan PE teachers because they could test their own abilities and through feedback and reflection came to realize what they needed to learn to become better PE teachers. Giving feedback to each other was an unusual practice for the Afghan PE teachers, as they were not used to relating to each other's work or commenting directly to their colleagues. They were very polite towards each other and it was difficult for them to be honest if they had adjustments to suggest to colleagues. As the project progressed, the participants' perception of the feedback process changed from being a negative experience to being more positive and constructive. To enhance long-term sustainability of the sports program, it was important to ensure cooperation amongst the Afghan PE teachers and one way in which this was reinforced was by using each other as observers during lessons and then providing feedback. Following feedback sessions, one of the Afghan teachers stated that these events had triggered thinking and reflection on what they were doing for the children during PE.

As the Danish facilitators had more teaching experience, and at times more knowledge of practical sports-related issues, their role on some occasions dominated that of the local teachers. To more evenly distribute the power among the team members, the Danish staff involved local staff as much as possible, especially in relation to culturally and contextually appropriate matters where they became the experts.

\section{THE VALUE OF THE METHODS}

This project, implemented in Afghanistan, serves as a role model for inclusiveness. By working with marginalized street working children and youth as the end beneficiary group, the project's purpose is to increase their opportunities for inclusion in social activities and make them part 
of a bridge-building process between public schools and Aschiana through sports tournaments. This is understood as civil society activity. The girls and boys involved in the project were afforded equal opportunities. This was an attempt, more broadly speaking, to contribute to gender equality in the Afghan society.

A project is worth the effort when participants learn something useful from the experience and our experience is that learning comes from challenges and reflections. It seemed to be the case for both the GES staff and the Afghan $\mathrm{PE}$ teachers involved in the project that they developed each other's minds and perspectives. Reaching the project goals proved complex and challenging, calling for enormous efforts in communication and organization along the way, and requiring resolution of many challenges and adjustments to continue the journey.

There is no doubt that the most important achievements of the project occurred during meetings between participants, through idea and value sharing. The basis for this was social relations and open-mindedness created within the group of participants throughout the whole process. This process is crucial to laying the path for goal achievement.

\section{For more information visit:}

www.globaledusport.org and www.Aschiana.com

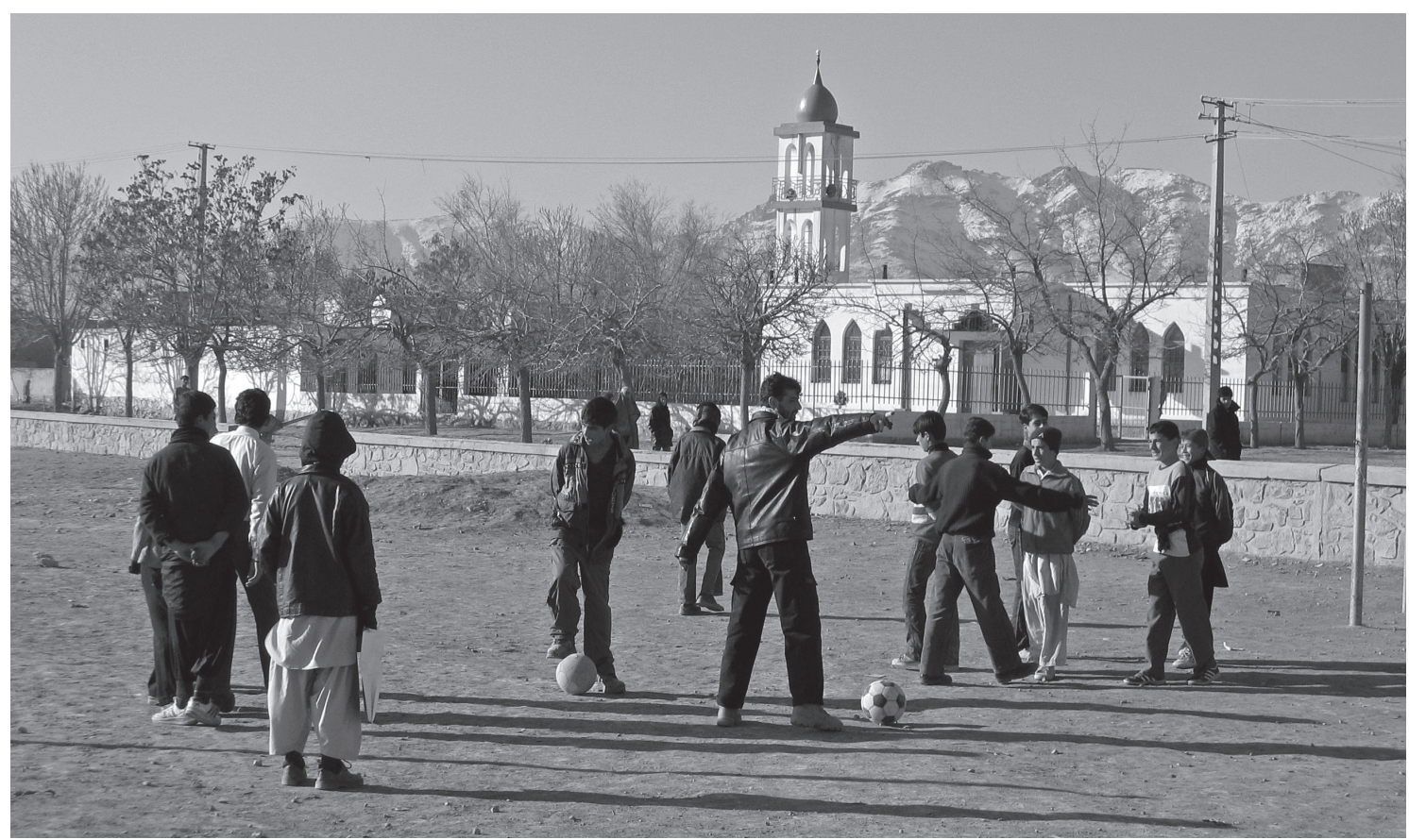

The teacher organizes soccer activities in a public playing field in Kabul (Photo: Majbrit Mouridsen). 